\title{
PENGARUH PENGGUNAAN MODEL KEPALA BERNOMOR TERHADAP KETERAMPILAN MENULIS TEKS PIDATO SISWA KELAS IX G SMP NEGERI 2 KOTA JAMBI TAHUN AJARAN 2017/2018
}

\author{
Risky Gustaviana?, \\ Ade Rahima $^{10}$, Sujoko ${ }^{11}$
}

\begin{abstract}
The purpose of this study is to describe the effect of the use of numbered head models to the writing skills of speech text of grade IX students SMP Negeri 2 Kota Jambi Academic Year 2017/2018. The type of research used is quantitative and analyzed descriptively. The population that becomes the unit of analysis is all students of class IX G SMP Negeri 2 Kota Jambi as many as 36 students. The study used total sampling. Data collection techniques were conducted with questionnaires and assignments. Based on the results of the analysis, obtained the average value of post-test that has been taught by using the head model numbered 81.25 very good while the average value of pre-test is 71.25 good. This is evidenced by hypothesis testing using $t$ test, in testing the hypothesis obtained value t count sebessar 9.881 greater than the value of ttable with dk 35 of 2.042 which means Ha accepted. Based on the hypothesis test that the numbered head model can be used by the teacher in speech writing lesson.
\end{abstract}

Keywords: Write, Speech Text, Numbered Head Models.

\footnotetext{
${ }^{9}$ Mahasiswa Program Studi Pendidikan Bahasa dan Sastra Indonesia Universitas Batanghari

${ }^{10}$ Dosen Program Studi Pendidikan Bahasa dan Sastra Indonesia Universitas Batanghari

${ }^{11}$ Dosen Program Studi Pendidikan Bahasa dan Sastra Indonesia Universitas Batanghari
} 


\section{PENDAHULUAN}

Bahasa Indonesia dijadikan salah satu mata pelajaran di sekolah. Mata pelajaran bahasa Indonesia mempelajari berbagai ranah keilmuan berbahasa dan juga keterampilan berbahasa. "Pembelajaran bahasa Indonesia memiliki empat keterampilan berbahasa diantaranya keterampilan menyimak, berbicara, membaca, dan menulis" (Tarigan, 2008: 1). Keempat keterampilan berbahasa tersebut dipelajari secara berurutan diawali dengan keterampilan menyimak sampai keterampilan menulis. Penelitian ini terkait dengan pembelajaran keterampilan menulis.

Hasil wawancara penulis dengan beberapa siswa (Sabtu, 11 November 2017) bahwa ada dua aspek yang disampaikan oleh siswa pertama mereka merasa berminat dan kedua mereka justru tidak berminat. Menurut siswa yang berminat memiliki kesulitan untuk mengungkapkan tata bahasa yang baku dalam menulis teks pidato, dan siswa yang tidak berminat mengatakan bahwa mereka kesulitan untuk merangkai kata-katanya untuk menulis teks pidato. Hal itu dikarenakan teks pidato dianggap sulit dipahami sehingga kurang menarik minat mereka. Terdapat banyak model pembelajaran yang dapat dipergunakan dalam pembelajaran bahasa Indonesia khususnya menulis teks pidato.

Model pembelajaran yang baik dan sesuai akan mengantarkan pada ketercapaian tujuan pembelajaran itu sendiri. Hasil wawancara penulis dengan guru bahasa Indonesia Titi Handayani (Sabtu, 11 November
2017) menyatakan bahwa model pembelajaran kepala bernomor ini belum pernah digunakan oleh guru dalam mengajar di sekolah khususnya untuk penulisan teks pidato. Model kepala bernomor merupakan sesuatu yang menarik untuk dilakukan sehingga siswa merasa proses belajar sambil bermain. Berdasarkan langkah-langkah model kepala bernomor dilaksanakan seperti bermain dimana siswa diberikan sebuah topi yang diberikan nomor untuk pembelajaran menulis teks pidato, sehingga diharapkan siswa menjadi tidak jenuh.

Pembelajaran sebagai proses tindakan dalam mempelajari suatu materi yang berpusat pada peserta didik. "Pembelajaran adalah suatu kombinasi yang tersusun meliputi unsur-unsur manusiawi, material, fasilitas, perlengkapan, dan prosedur yang saling mempengaruhi mencapai tujuan pembelajaran" (Hamalik, 2008: 57). Dalam proses pembelajaran tentu ada yang namanya kurikulum. Tanpa kurikulum yang jelas sebagai acuan, maka pembelajaran tidak akan berlangsung secara afektif.

Kurikulum dan pembelajaran merupakan dua hal yang tidak dapat dipisahkan. Sebagai suatu rencana atau program, kurikulum tidak akan bermakna manakala tidak diimplementasikan dalam bentuk pembelajaran. "Kurikulum adalah seperangkat rencana dan pengaturan mengenai tujuan, isi, dan bahan pelaksanaan serta cara yang digunakan sebagai pedoman penyelenggaraan kegiatan pembelajaran untuk mencapai tujuan pendidikan tertentu" (Darmadi, 2010: 
233). Kurikulum sebagai aktivitas apa saja yang dilakukan sekolah dalam rangka mempengaruhi peserta didik dalam belajar untuk mencapai suatu tujuan.

Dalam kurikulum tingkat satuan pendidikan terdapat pembelajaran keterampilan menulis teks pidato ada di pelajaran Standar Kompetensi (SK) 12 Mengungkapkan pikiran, perasaan, dan informasi dalam bentuk teks pidato. Kompetensi Dasar (KD) 12.2 Menulis teks pidato/ceramah/khotbah dengan sistematika dan bahasa yang efektif (Sadikin, dkk, 2006:136).

Menulis sebagai kegiatan pengungkapan ide, gagasan pikiran atau perasaan secara tertulis. "Menulis merupakan menurunkan atau melukiskan lambang-lambang grafik yang menggambarkan suatu bahasa yang dipahami oleh seseorang, sehingga orang-orang lain dapat membaca lambang-lambang grafik itu" (Tarigan, 2008: 22). Oleh karena itu, menulis juga bisa menambah kreativitas pola pikir bagi siswa. Banyak jenis kegiatan menulis di dalam pembelajaran bahasa dan sastra Indonesia yang dapat kita gunakan salah satunya menulis teks pidato.

Pidato dapat dimaknai sebagai wacana yang disiapkan untuk diucapkan di depan khalayak dengan maksud agar orang yang mendengarkan, mengetahui, memahami, dan diharapkan bersedia melaksanakan isi dari wacana yang diucapkan. "Pidato adalah pengungkapan pikiran dalam bentuk kata-kata yang ditunjukkan kepada orang banyak, atau wacana yang disiapkan untuk diucapkan di depan khalayak" (Hadinegoro, 2009:1). Pidato merupakan seni berbicara di hadapan umum. "Pidato biasanya digunakan oleh seorang pemimpin untuk menyampaikan gagasannya, pandangan-pandangan, atau visinya kepada masyarakat umum" (Handoko, 2011:39). Pidato merupakan kecakapan dalam menyampaikan kata-kata kepada orang lain secara lisan.

Penilaian suatu tindakan atau proses untuk menentukan nilai dari suatu tindakan atau proses untuk menentukan nilai dari sesuatu. "Evaluai adalah suatu tindakan atau suatu proses untuk menentukan nilai dari pada sesuatu" Brown (dalam Sunartana, dkk, 1983: 1). Penilaian dapat diartikan sebagai suatu tindakan atau suatu proses untuk menetukan nilai.

Penilaian menulis teks pidato harus mengukur tujuan yang ingin dicapai sesuai dengan paparan indikator dan tujuan pembelajaran pada rencana pembelajaran. Selain itu penilaian juga perlu dilaksanakan dengan pemilihan bentuk yang tepat. Namun, alat yang dibuat disesuaikan dengan tingkat kemampuan dalam keluasan kurikulum yang dikehendaki. Adapun komponenkomponen dalam penilaian menulis teks pidato (Nurgiyantoro, 2010: 307308), yaitu sebagai berikut.

1. Isi

Isi merupakan satu gagasan dari keseluruhan dari teks pidato, isi pidato harus sesuai dengan topik yang diangkat dalam berpidato.

2. Gaya bahasa

Gaya bahasa dalam berpidato adalah penggunaan kata-kata kiasan yang tepat ketika berpidato. Tujuan menggunakan gaya bahasa ini agar apa yang disampaikan 
dalam berpidato dapat menimbulkan perasaan tertentu dalam hati pendengar/audiens.

3. Tata bahasa

Tata bahasa merupakan susunan kata-kata dalam, menulis teks pidato sehingga teks pidato yang dibacakan lebih rapi. Tata bahasa menulis teks pidato lebih detail dan perlu memperhatikan penggunaan tanda baca.

4. Diksi

Dalam membuat teks pidato diksi atau pilihan kata sangat diperlukan.Diksi atau pilihan kata dapat menunjang isi teks pidato.Memilih kata yang tepat dapat mewakili pesan yang ingin kita sampaikan, yang tepat bagi audiens, dan yang dapat membawa tujuan dari komunikasi yang kita lakukan dalam berpidato.

5. Struktur pidato

Dalam membuat teks pidato, struktur pidato harus diperhatikan. Struktur pidato dimulai dari pembukaan, isi, dan penutup. Dengan memperhatikan struktur pidato agar teks pidato terlebih terstruktur dan tersusun rapi sehingga teks pidato tidak terasa terbolak-balik.

Model pembelajaran suatu rencana atau pola yang dapat digunakan untuk membentuk kurikulum, merancang bahan-bahan pembelajaran, dan membimbing tindakan/aksi pengajar dalam pembelajaran di kelas. "Model pembelajaran adalah pola yang digunakan sebagai pedoman dalam merencanakan pembelajaran di kelas maupun tutorial" (Suprijono, 2009: 46). Model pembelajaran pada dasarnya merupakan bentuk pembelajaran yang tergambar dari awal sampai akhir yang disajikan secara khas oleh guru.

Model pembelajaran kepala bernomor memiliki ciri khas dimana guru hanya menunjuk seorang siswa untuk mewakili kelompoknya tanpa memberitahu terlebih dahulu siapa yang akan mewakili kelompoknya tersebut. "Model kepala bernomor adalah salah satu tipe dari pembelajaran koperatif dengan sintaksis: pengarahan, buat kelompok heterogen dan tiap siswa memiliki nomor tertentu, berikan persoalan materi bahan ajar" (Ngalimun, 2015: 236). Model pembelajaran kepala bernomor yang lebih mengedepankan kepada aktivitas siswa dalam mencari, mengolah, dan melaporkan informasi dari berbagai sumber yang akhkirnya dipresentasikan di depan kelas.

Model pembelajaran kepala bernomor merupakan model belajar di mana siswa mengerjakan secara berkelompok. Menurut Huda (2011:138) langkah-langkah model kepala bernomor di antaranya:

1. Siswa dibagi dalam kelompok, masing-masing siswa dalam kelompok diberi nomor.

2. Guru memberikan tugas/pertanyaan dan masingmasing kelompok mengerjakannya.

3. Kelompok berdiskusi untuk menemukan jawaban yang dianggap paling benar dan memastikan semua anggota kelompok mengetahui jawaban tersebut.

4. Guru memanggil salah satu nomor. Siswa dengan nomor yang 
dipanggil mempresentasikan jawaban hasil diskusi kelompok mereka.

5. Kesimpulan.

6.

\section{METODE PENELITIAN}

Metode penelitian ini tergolong metode deskriptif kuantitatif, yaitu suatu penelitian yang berusaha menjabarkan peristiwa dan fenomena yang ada pada masa sekarang, suatu pendekatan dalam melakukan penelitian yang berorientasiakan realitas, gejala atau fenomena yang terjadi bersifat relatif tetap, dan konkrit. Tujuan penelitian deskriptif ini untuk memberikan gambaran yang jelas dan akurat tentang material atau fenomena yang sedang diselidiki. Dengan demikian penelitian ini menggunakan metode deskriptif kuantitatif untuk menggambarkan pengaruh penggunaan model kepala bernomor terhadap keterampilan menulis teks pidato siswa kelas IX G SMP Negeri 2 Kota Jambi Tahun Ajaran 2017/2018.

Instrumen penelitian merupakan alat yang digunakan penulis untuk mendapatkan data. "Instrumen penelitian adalah alat atau fasilitas yang digunakan oleh penulis dalam mengumpulkan data agar pekerjaannya lebih mudah dan hasilnya lebih baik, dalam arti lebih cermat, lengkap, dan sistematis sehinga lebih mudah diolah" (Arikunto, 2006:160). Dalam penelitian ini instrumen yang digunakan berupa penugasan dan angket.

Teknik pengumpulan data merupakan cara-cara yang paling strategis yang digunakan oleh seorang peneliti guna untuk mengumpulkan data dalam penelitian, karena tujuan utama dalam penelitian adalah mendapatkan data. Pengumpulan data dapat dilakukan dalam berbagai setting, berbagai sumber, berbagai cara. Pada kelas subjek menggunakan model kepala bernomor. Teknik pengumpulan data yang digunakan adalah sebagai berikut:

1. Penugasan

"Penugasan adalah sebagai suatu cara interaksi belajar mengajar yang ditandai dengan adanya tugas dari guru yang dikerjakan peserta didik di sekolah ataupun di rumah secara perorangan atau kelompok" (Mulyani, 1999: 151). Kegunaan kriteria penugasan diberikan untuk mengetahui hasil belajar siswa dalam pengaruh penggunaan model kepala bernomor terhadap keterampilan menulis teks pidato siswa kelas IX G SMP Negeri 2 Kota Jambi Tahun Ajaran 2017/2018.

2. Angket

Angket atau kuisioner adalah "alat untuk mengumpulkan data yang berupa daftar pertanyaan yang disampaikan kepada responden untuk dijawab secara tertulis" (Riyanto, 2011: 71). Angket terbagi menjadi dua yaitu:

a. Angket Terbuka

Meminta pendapat responden sesuai dengan pendapatnya sendiri dan diungkapkan dengan kata-katanya sendiri.Berguna untuk tahap eksplorasi tetapi kadangkadang dapat mengundang respon yang sulit untuk dianalisis.

b. Angket Tertutup atau PilihanGanda 
Meminta responden untuk memilih pertanyaan atau deskripsi yang sudah tersedia dalam angket, sehingga menutup kemungkinan bagi responden untuk mengungkapkan pendapat, perasaan, penilaian dan lainnya.

Penelitian ini memiliki beberapa data. Menurut (Siswantoro, 2010: 70) "Data adalah sumber informasi yang akan diseleksi sebagai bahan analisis". Data terbagi menjadi dua yaitu data primer dan data sekunder.

\section{Data primer}

"Data primer adalah data yang langsung memberikan data kepada pengumpulan data" (Sugiyono, 2005: 308). Data primer dalam penelitian ini diperoleh secara langsung dari angket, dan data primer dalam penelitian ini adalah hasil penugasan siswa dalam pembelajaran menulis teks pidato dengan model kepala bernomor dengan menggunakan total sampling.

2. Data Sekunder

"Data sekunder merupakan data yang tidak langsung memberikan data kepada pengumpulan dara" (Sugiyono, 2005: 309). Data sekunder dalam penelitian ini,adalah buku-buku yang dijadikan sebagai penunjang bahan dalam penelitian ini, penulis peroleh atau menggunakan dari data pustaka.

Teknik analisis data dalam penelitian bertujuan untuk menguji kebenaran hipotesis yang dilakukan dalam penelitian ini. Data yang dianalisis adalah skor hasil penugasan akhir siswa kelas subjek sebelum analisis dilakukan terlebih dahulu dilakukan uji normalitas dan uji homogenitas.

\section{HASIL DAN PEMBAHASAN}

Penelitian menganalisis data dengan menggunakan rumus uji-t. Untuk mengetahui hipotesis, penulis menganalisis data dengan menggunakan rumus $\mathrm{t}_{\text {-hitung }}$ berikut:

$$
\begin{aligned}
& M d=\frac{\sum d}{N}=\frac{365}{36}=10,138 \\
& t=\frac{M d}{\sqrt{\frac{\sum x^{2} d}{N(N-1)}}} \\
& t=\frac{10,138}{\sqrt{\frac{1326,844}{36(36-1)}}} \\
& t=\frac{10,138}{\sqrt{\frac{1326,844}{36(35)}}} \\
& t=\frac{10,138}{\sqrt{\frac{1326,844}{1260}}} \\
& t=\frac{10,138}{\sqrt{1,053}} \\
& t=\frac{10,138}{1,026} \\
& t=9,881
\end{aligned}
$$

Dengan taraf signifikasi $\alpha=0,05$ dan derajat kebebasan $\mathrm{dk}=(\mathrm{n}-1), \mathrm{dk}=$ $(36-1)=35$. Dari daftar distribusi $t$, diperoleh nilai dk 35 sebesar 2, 042. Maka diperoleh nilai $t_{\text {hitung }}(9,881)>$ $t_{\text {tabel }}(2,042)$ dengan demikian hipotesis yang berbunyi "Pengaruh model kepala bernomor terhadap keterampilan menulis teks pidato siswa kelas IX G SMP Negeri 2 Kota Jambi" dapat diterima dengan baik.

Hasil Analisis Respon Siswa Melalui Penggunaan Model Kepala 
Bernomor Pengumpulan data melalui penyebaran angket juga dilakukan oleh penulis. Hal ini untuk mengetahui respon yang diberikan oleh siswa terhadap model kepala bernomor pada pembelajaran bahasa Indonesia. Respon yang diberikan oleh siswa dapat dilihat pada tabel berikut ini:

Tabel 1. Respon Siswa Terhadap Model Kepala Bernomor

\begin{tabular}{|c|c|c|c|c|c|c|}
\hline \multirow{2}{*}{$\begin{array}{l}\mathbf{N} \\
\mathbf{o}\end{array}$} & \multirow[t]{2}{*}{ PERNYATAAN } & \multicolumn{5}{|c|}{ Pilih Jawaban } \\
\hline & & ST & $\mathbf{S}$ & KS & TS & STS \\
\hline 1 & $\begin{array}{l}\text { Saya suka tentang cara } \\
\text { digunakan guru dalam menar yang } \\
\text { materi. }\end{array}$ & $\begin{array}{c}15 \\
41,6 \%\end{array}$ & $\begin{array}{c}21 \\
58,4 \%\end{array}$ & $\begin{array}{c}0 \\
0 \%\end{array}$ & $\begin{array}{c}0 \\
0 \%\end{array}$ & $\begin{array}{c}0 \\
0 \%\end{array}$ \\
\hline 2 & $\begin{array}{l}\text { Saya dapat memahami } \\
\text { digunakan guru dalam } \\
\text { materi pembelajaran. }\end{array}$ & $\begin{array}{c}17 \\
47,2 \%\end{array}$ & $\begin{array}{c}19 \\
52,8 \%\end{array}$ & $\begin{array}{c}0 \\
0 \%\end{array}$ & $\begin{array}{c}0 \\
0 \%\end{array}$ & $\begin{array}{c}0 \\
0 \%\end{array}$ \\
\hline 3 & $\begin{array}{l}\text { Saya tertarik dengan model kepala bernomor } \\
\text { dalam pembelajaran menulis teks pidato. }\end{array}$ & $\begin{array}{c}15 \\
41,6 \%\end{array}$ & $\begin{array}{c}20 \\
55,6 \%\end{array}$ & $\begin{array}{c}1 \\
2,8 \%\end{array}$ & $\begin{array}{c}0 \\
0 \%\end{array}$ & $\begin{array}{c}0 \\
0 \%\end{array}$ \\
\hline 4 & $\begin{array}{l}\text { Saya mengalami kesulitan terhadap model } \\
\text { kepala bernomor dalam pembelajaran } \\
\text { menulis teks pidato. }\end{array}$ & $\begin{array}{c}0 \\
0 \%\end{array}$ & $\begin{array}{c}0 \\
0 \%\end{array}$ & $\begin{array}{c}0 \\
0 \%\end{array}$ & $\begin{array}{c}14 \\
38,8 \%\end{array}$ & $\begin{array}{c}22 \\
61,2 \\
\%\end{array}$ \\
\hline 5 & $\begin{array}{l}\text { Penggunaan model kepala bernomor efektif } \\
\text { digunakan untuk penyampaian materi } \\
\text { menulis teks pidato. }\end{array}$ & $\begin{array}{c}16 \\
44,4 \%\end{array}$ & $\begin{array}{c}20 \\
55,6 \%\end{array}$ & $\begin{array}{c}0 \\
0 \%\end{array}$ & $\begin{array}{c}0 \\
0 \%\end{array}$ & $\begin{array}{c}0 \\
0 \%\end{array}$ \\
\hline 6 & $\begin{array}{l}\text { Saya merasa senang atau termotivasi belajar } \\
\text { dengan model kepala bernomor dalam } \\
\text { pembelajaran menulis tekspidato. }\end{array}$ & $\begin{array}{c}17 \\
47,2 \%\end{array}$ & $\begin{array}{c}19 \\
52,8 \%\end{array}$ & $\begin{array}{c}0 \\
0 \%\end{array}$ & $\begin{array}{c}0 \\
0 \%\end{array}$ & $\begin{array}{c}0 \\
0 \%\end{array}$ \\
\hline 7 & $\begin{array}{l}\text { Penggunaan model kepala bernomor dalam } \\
\text { pembelajaran menulis teks pidato membuat } \\
\text { saya lebih mudah berinteraksi dengan } \\
\text { teman-teman. }\end{array}$ & $\begin{array}{c}15 \\
41,7 \%\end{array}$ & $\begin{array}{c}21 \\
58,3 \%\end{array}$ & $\begin{array}{c}0 \\
0 \%\end{array}$ & $\begin{array}{c}0 \\
0 \%\end{array}$ & $\begin{array}{c}0 \\
0 \%\end{array}$ \\
\hline 8 & $\begin{array}{l}\text { Suasana pembelajaran di kelas } \\
\text { menyenangkan melalui penggunaan model } \\
\text { kepala bernomor. }\end{array}$ & $\begin{array}{c}27 \\
75 \%\end{array}$ & $\begin{array}{c}9 \\
25 \%\end{array}$ & $\begin{array}{c}0 \\
0 \%\end{array}$ & $\begin{array}{c}0 \\
0 \%\end{array}$ & $\begin{array}{c}0 \\
0 \%\end{array}$ \\
\hline 9 & $\begin{array}{l}\text { Saya merasa senang ketika guru menyuruh } \\
\text { berpikir dan berdiskusi. }\end{array}$ & $\begin{array}{c}24 \\
67 \% \\
\end{array}$ & $\begin{array}{c}12 \\
33 \% \\
\end{array}$ & $\begin{array}{c}0 \\
0 \% \\
\end{array}$ & $\begin{array}{c}0 \\
0 \% \\
\end{array}$ & $\begin{array}{c}0 \\
0 \% \\
\end{array}$ \\
\hline $\begin{array}{l}1 \\
0\end{array}$ & $\begin{array}{l}\text { Saya suka ketika guru meminta untuk } \\
\text { menjelaskan hasil diskusi di depan kelas. }\end{array}$ & $\begin{array}{c}17 \\
47,3 \% \\
\end{array}$ & $\begin{array}{c}16 \\
53,3 \%\end{array}$ & $\begin{array}{c}3 \\
8,4 \%\end{array}$ & $\begin{array}{c}0 \\
0 \%\end{array}$ & $\begin{array}{c}0 \\
0 \%\end{array}$ \\
\hline
\end{tabular}

Berdasarkan analisis tabel yang telah dilakukan, maka dapat disimpulkan bahwa siswa memberikan respon yang positif terhadap pembelajaran menulis teks pidato dengan menggunakan model kepala bernomor.

Pada bagian ini akan ditemukan hasil penelitian pengaruh penggunan model kepala bernomor terhadap keterampilan menulis teks pidato siswa kelas IX G SMP Negeri 2 Kota Jambi Tahun Ajaran 2017/2018. Adapun deskripsi data hasil penelitian dan analisis adalah sebagai berikut.

Penelitian ini bertujuan untuk mengetahui pengaruh penggunan model kepala bernomor terhadap keterampilan menulis teks pidato siswa kelas IX G SMP Negeri 2 Kota Jambi Tahun Ajaran 2017/2018. Penelitian ini menggunakan kelas IX 
G dengan jumlah siswa sebanyak 36 orang. Penelitian ini menggunakan satu kelas sampel, tapi dalam proses pengambilan data dilakukan pretest dan postest.

Hasil belajar juga menunjukkan bahwa model kepala bernomor memberikan nilai yang baik terhadap hasil keterampilan menulis teks pidato siswa. Hal ini dapat dilihat dari nilai rata-rata postets 81,25 yaitu nilai setelah menggunakan model kepala bernomor lebih tinggi dibandingkan nilai rata-rata pretest 71,25 yaitu saat tidak mendapat perlakuan.

Sejalan dengan angket yang mayoritas siswa memilih setuju artinya model kepala bernomor mendapat respon positif, uji hipotesis juga menunjukkan bahwa penggunaan model kepala bernomor memberikan respon positif terhadap keterampilan menulis pidato,dari uji hipotesis yang dilakukan dimana nilai $t_{\text {hitung }}$ lebih besar dari nilai $t_{\text {tabel }}$ dengan nilai $t_{\text {hitung }} 9,881>t_{\text {tabel }} 2,042$. Dengan demikian, diasumsikan $\mathrm{Ha}$ diterima dan Ho ditolak. Jadi dapat disimpulkan bahwa model kepala bernomor menjadikan kemampuan pembelajaran menulis teks pidato anak lebih baik karena memiliki ideide yang lebih bervariasi. Hal ini dikuatkan oleh angket dimana anak memberikan respon yang positif terhadap penggunaan model kepala bernomor dalam pembelajaran keterampilan menulis teks pidato.

\section{KESIMPULAN}

Berdasarkan hasil analisis yang dilakukan, diperoleh nilai rata-rata post-test yang telah diajarkan dengan menggunakan model kepala bernomor sebesar 81,25 sangat baik.
Sedangkan nilai rata-rata pre-test adalah 71,25 baik. Berdasarkan pengujian hipotesis diperoleh kesimpulan bahwa penggunaan model kepala bernomor berpengaruh terhadap hasil pembelajaran menulis teks pidato siswa kelas IX G SMP Negeri 2 Kota Jambi tahun ajaran 2017/2018. Hal ini dibuktikan dengan pengujian hipotesis menggunakan uji t. Dalam pengujian hipotesis diperoleh nilai $t_{\text {hitung }}$ sebesar 9,881 lebih besar dari nilai $t_{\text {tabel }}$ dengan $\mathrm{dk}$ 35 sebesar 2,042 yang artinya $\mathrm{H}_{\mathrm{a}}$ diterima. Hal ini dikuatkan dengan hasil dari angket dimana mayoritas siswa memilih setuju terhadap penggunaan model kepala bernomor.

\section{DAFTAR PUSTAKA}

Arikunto, Suharsimi. 2006. Prosedur Penelitian Suatu Pendekatan Praktik. Jakarta: Rineka Cipta.

Darmadi, Hamid. 2010. Kurikulum Pendidikan. Yogyakarta: Kanisius.

Hadinegoro, Luqman. 2009. Teknik Seni Berpidato Mutakhir. Yogyakarta: Absolut.

Hamalik, Oemar. 2008. Kurikulum dan Pembelajaran. Jakarta: Bumi Aksara.

Handoko, Hands. 2011. Seni Pidato $M C$. Yogyakarta: Damai Media.

Huda, Miftahul. 2011. Cooperative Learning. Yogyakarta: Pustaka Belajar.

Kustina, Rika. 2015. Pengaruh Pembelajaran Kooperatif Tipe Numbered Head Together (NHT) Terhadap Kemampuan Menyusun Teks Cerpen 
Berdasarkan Struktur Teks pada Siswa Kelas VII SMP Negeri 17 Banda Aceh. Jurnal Metamorfosa, vol 3 no 2 tahun 2015.

Mulyani. 1999. Strategi Belajar Mengajar. Jakarta: Dirjen Dikti.

Ngalimun. 2015. Strategi dan Model Pembelajaran. Yogyakarta: Aswaja Pressindo.

Nurgiyantoro, Burhan. 2010. Penilaian Pembelajaran Bahasa. Yogyakarta: BPFE.

Riyanto, Agus. 2011. Buku Ajar Metodologi Penelitian. Jakarta: EGC.

Sadikin, Asep Ganda. 2006. Bahasa Indonesia. Bandung: Media Pratama.

Sugiyono. 2005. Metode Penelitian Kuantitatif Kualitatif dan $R \& D$. Bandung: Alfabeta.

Sunartana, Nurkancana. 1983. Evaluasi Pendidikan. Surabaya: Usaha Nasional.

Suprijono, Agus. 2009. Cooperative Learning. Yogyakarta: Pustaka Belajar.

Tarigan, Henry Guntur. 2008. Menulis Sebagai Suatu Keterampilan Berbahasa. Bandung: Angkasa.

Siswantoro. 2010. Metode Penelitian Sastra. Yogyakarta: Pustaka Belajar.

Yeti, Nofrida. 2016. Pengaruh Model Pembelajaran Kooperatif Numbered Head Togethe Terhadap Kemampuan Memahami Teks Cerpen Siswa Kelas VII SMP Negeri 3 Payakumbuh. Jurnal Pendidikan Bahasa dan Sastra
Indonesia, vol 5 no 2 tahun 2016. 